\title{
Interest of late cerclage on open cervix with amniotic membrane's hernia in an African environment. Review of I I collected cases at Yopougon University hospital in Abidjan (Ivory Coast, West Africa)
}

\begin{abstract}
Objective: To demonstrate effective strapping emergency in therapeutic management of threat with open-cervix.

Methodology: We conducted a descriptive cohort study at Yopougon Abidjan (Côte d'Ivoire) University Hospital. Over a period of two years (February 2015 to January 2017), the study concerned 11 gestantes who presented a severe threat of late miscarriage with the opened cervix, protrusion and intact membranes in the second trimester of Pregnancy. For all pregnant, a strapping of the cervix has been performed according to Mac Donald's procedure.
\end{abstract}

Results: Mean's age of patients was 30 years, $27.30 \%$ primigravida and $36.40 \%$ nulliparous. More than half $(55 \%)$ had a history of abortion. Symptomatology was dominated by pelvic pain $(63.60 \%)$. The average gestational age at the time of strapping was 20 weeks. Average duration of the interventions was $12,27 \mathrm{~min}$ and hospitalization of pregnant after cerclage was 3 days. Following up was marked by a new hospitalization in 3 patients, because of membrane's rupture at 31 weeks of pregnancy.

Average gestational age for childbirth was 36 weeks, $82 \%$ of births by caesarean section. $64 \%$ of children were born with a score of APGAR greater than 7 at the first minute. No cases of newborn death have been noted. Average time between strapping and childbirth was 115 days or 15 weeks.

Conclusion: Emergency cervical strapping is used to prolong the duration of pregnancy and to reduce risk of high prematurity, thereby improving fetus viability and prognosis.

Keywords: cervical strapping, threat of late miscarriage, cervical incompetenceprematurity
Volume 9 Issue 6 - 2018

\section{Fanny Mohamed, Koffi Abdoul, Konan Jean Marie, Aka Edele,Adjoussou Stephane, Olou Luc, Fomba Minata, Horo Apollinaire, Kone Mamourou}

Gynecology Department of the University and Hospital Center of Yopougon, Abidjan, Côte d'lvoire

Correspondence: Fanny Mohamed, Gynecology Department of the University and Hospital Center of Yopougon,Abidjan, Côte d'Ivoire, 2I BP 632 Abidjan 21, Côte d'lvoire,

Email monfanny@yahoo.fr, mohabfanny@gmail.com

Received: November 15, 2018 | Published: December 12 2018

\section{Introduction}

Late miscarriage is defined, classically, as the outcome of pregnancy in its second trimester. According to the French National College of Gynecologists and obstetricians, This is spontaneous expulsion of uterine contents, before 22 weeks of amenorrhea. ${ }^{1}$ If World health organization (WHO) evaluate fetal viability at 22 weeks, actual limits of late miscarriage and preterm delivery are variable across regions and medical teams according to equipment to take care of newborns. ${ }^{2}$

In contrast to highly medical countries where therapeutic progress has improved the prognosis of these preterm evictions, in subSaharan Africa the mortality and fetal morbidity of these spontaneous miscarriages remain high low-and middle-income countries record $98 \%$ of neonatal deaths.

Diagnosis of late miscarriage threat is based by dilation and/or shortening of the cervix in the second trimester of Pregnancy. The risk is an expulsion of the fetus in the absence of urgent and rapid therapeutic management.
Treatment of this threat is intended to delay fetal expulsion if possible to reduce the morbidity mortality associated with fetal immaturity. Therapeutic possibilities are well known based on symptomatic and causative medicinal means with hospitalization of sometimes long duration. ${ }^{4}$ For threat of miscarriage in the second trimester of pregnancy with an open cervix, we practice in our service a strapping. This technique consists in placing a strip around cervix to provide mechanical support and thus reduce the risk of premature birth. Cervical strapping is usually done for preventive purposes at the end of the first trimester of Pregnancy. However, efficacy and safety of this procedure in the second trimester of pregnancy remains controversial. ${ }^{5}$ Through this study, we would like to report our experience in this therapeutic approach to the threat of miscarriage with open cervix.

Specific objectives of this study are to describe the epidemioclinical characteristics of pregnant, appreciate the effectiveness of strapping in outcome of these pregnancies with a circled cervix. Main objective is to contribute to improve management of these 
pregnancies at fetal loss risk in a low-income population where long-term hospitalization is at an additional cost at the expense of Pregnancy.

\section{Methodology}

This was a descriptive cohort study conducted from February 2015 to January 2017, or a 2-year period, in the gynecology and obstetrics Department of the Yopougon University Hospital in Abidjan (Côte d'Ivoire). Study concerned the pregnant of a single or twin pregnancy in the second trimester of pregnancy (betwen 16 and 27 weeks) who were admitted for threat of miscarriage. Gestational age was calculated from the last menstrues and confirmed by an early ultrasound done in the first trimester of Pregnancy. Patients selected for the study had a gaping cervix with a hernia of the amniotic membranes regardless of the length of the cervix (Figure 1). Not been included, patients with severe maternal pathology that could compromise the evolution of pregnancy such as hypertensive arterial, diabetes, HIV Infection. Cerclage was carried out considering the classical contraindications of the uterine cerclage (absence of amniotic infection, fetal malformation absence, consent of the pregnant). So we retained for the study 11 cases.

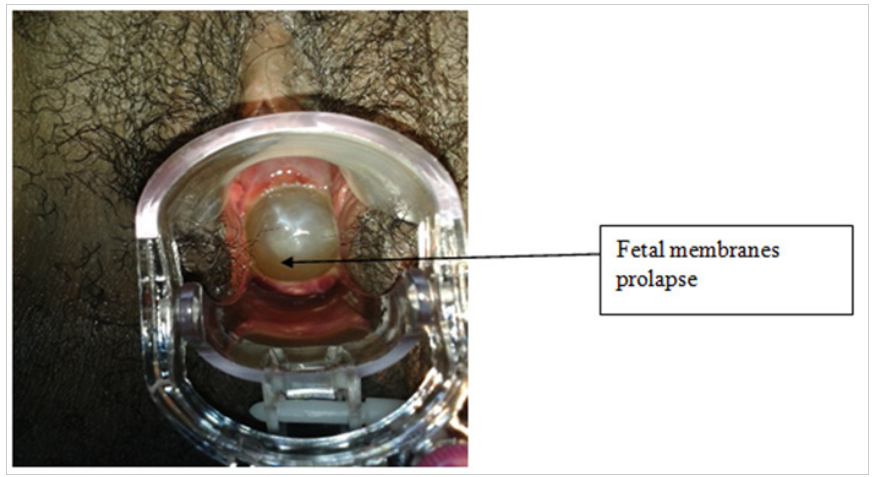

Figure I Opened cervix with amniotic membrane's hernia seen in the speculum during diagnosis.

\section{Preparing strapping}

Patients were hospitalized immediately after diagnosis confirmed. An obstetric ultrasound by same operator in order to check fetal morphology, vitality and length of cervix have been done. An infectious balance sheet (Vaginal swab, CRP, cytobacterioligical urine exam, dipstick urine test, Blood cell count) and a pre-operative assessment (Electrocardiogram, blood crasis) were also required. Patient was kept in a Trendelenburg position. As soon as the results of the negative infectious balance were obtained, strapping was performed.

\section{Strapping procedure}

Procedure was performed by the same operator under general anesthesia in Trendelenburg position with antispasmodic infusion (Phoroglucinol) and prophylaxis by $2 \mathrm{~g}$ of amoxicillin-acid clavulanic administered in preoperative.

After exposure of the cervix using vaginal valves, its seized with 2 Pozzi pliers, one of which is placed on the anterior lip and the other on the posterior lip, taking care not to transfix the collar for fear of breaking the membranes (Figure 2). Membranes are slowly repressed by a compress moistened with physiological serum mounted on a long clamp (Figure 3).

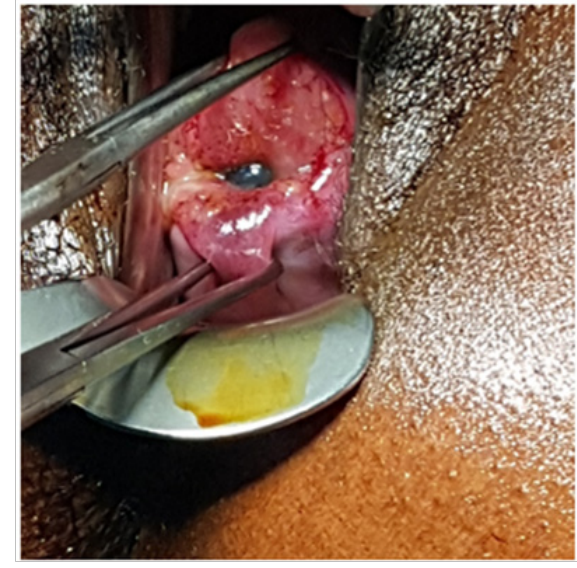

Figure 2 Pozzi pliers on the lips of opened cervix.

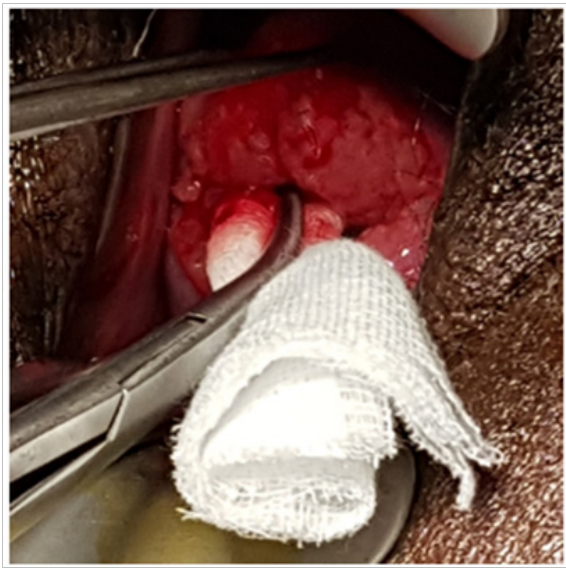

Figure 3 Amniotic membrane repressed using a physiological serum soaked compress.

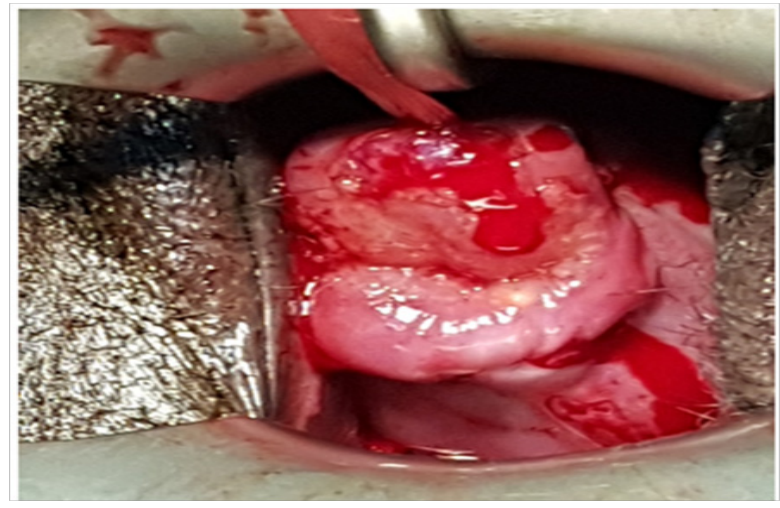

Figure 4 Closing cervix after removing Pozzi and compress clips, wire knotted at 12 o'clock.

While soft traction on the cervix using Pozzi pliers is carried out to cover the repressed membranes, intrafascial basting of the cervix is performed using mersilen strip with a length of $40 \mathrm{~cm}, 0.5 \mathrm{~cm}$ wide, with two needles of $48 \mathrm{~mm}$, curvature $1 / 2$, garter point (reference Ethicon Mersutures ( ${ }^{\mathbb{B}}$ RS22). Technique used was that of Mac Donald. Knot is made at 12 o'clock, during the gradual removal of the tongue clamp initially introduced into cervical channel (Figure 4). 
Intervention ends with administration in intrarectal of 2 suppositories of Ketoprofen $100 \mathrm{mg}$ extended 48 hours in hospitalization, associated with antispasmodics intravenously.

Parameters studied were epidemiological characteristics (maternal age, parity, history of miscarriage or pretherm delivery, abortion), Clinical aspects (gestational age at time of diagnosis, length and cervical dilatation, associated symptomatology), subsequent evolution of pregnancy (complications and becoming obstetric).

Data were collected from medical record and operated from Excel 2007 and Epi Info 7 software.

\section{Results}

\section{Epidemiological aspects}

Means age of our patients was 30, 27 years [23 -36 years]. General data are represented in Table 1.

Table I Epidemiological characteristics of patients

\begin{tabular}{|c|c|c|}
\hline & $\begin{array}{l}\text { Number } \\
\text { (N) }\end{array}$ & Percent(\%) \\
\hline \multicolumn{3}{|l|}{ Age (ans) } \\
\hline $20-24$ & I & 09,10 \\
\hline $25-29$ & 3 & 27,30 \\
\hline $30-34$ & 6 & 54,60 \\
\hline$>35$ & I & 09,10 \\
\hline \multicolumn{3}{|l|}{ Pregnancy history } \\
\hline First Pregnancy $(P=I)$ & 3 & 27,30 \\
\hline Pregnancy $(P=2,3)$ & 5 & 45,40 \\
\hline 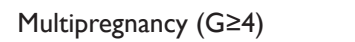 & 3 & 27,30 \\
\hline \multicolumn{3}{|l|}{ Parity } \\
\hline Nulliparous & 4 & 36,40 \\
\hline Primiparous (I) & 5 & 45,40 \\
\hline Pauciparous (2-3) & 2 & 18,20 \\
\hline \multicolumn{3}{|l|}{ History } \\
\hline Conization & 2 & 18,20 \\
\hline Synechia & 3 & 27,30 \\
\hline Incompetent cervico-isthmus & I & 09,10 \\
\hline Late miscarriage & 3 & 27,30 \\
\hline Abortion & 6 & 54,60 \\
\hline Preterm birth & 1 & 9,10 \\
\hline
\end{tabular}

\section{Clinical and therapeutic aspects}

These are carried over to Table 2. $3 / 4$ of patients (72.7\%) had a gestational age between 20 and 25 weeks at time of diagnosis. Mean gestational age was 20 weeks [17 - 25 weeks]. Average length of the cervix at ultrasound was measured at $22.18 \mathrm{~mm}$ [15-31mm]. Opening of the cervix to ultrasound was an average of $15.82 \mathrm{~mm}$ [8-24mm]. Mean duration of the intervention was 12.27 minutes [8-20mn]. We did not record any complication during the intervention. Hospitalization of pregnant after strapping lasted on average 3 days [2 -7 days].
Table 2 Clinical data

\begin{tabular}{|c|c|c|}
\hline & Number & Percent (\%) \\
\hline \multicolumn{3}{|l|}{ Gestational age (week) } \\
\hline$<20$ & 3 & 27,3 \\
\hline $20-25$ & 8 & 72,7 \\
\hline Mean gestational age (week) & 20 & \\
\hline \multicolumn{3}{|l|}{ Pregnancy type } \\
\hline Mono fetal & 10 & 90,9 \\
\hline Twin & I & 9,1 \\
\hline \multicolumn{3}{|l|}{ Symptomatology } \\
\hline Bleeding & I & 9,1 \\
\hline Pelvic pain & 7 & 63,6 \\
\hline Fever & 3 & 27,3 \\
\hline Vaginal discharge & 2 & 18,2 \\
\hline Urgency burns & 3 & 27,3 \\
\hline \multicolumn{3}{|l|}{ Cervix's length } \\
\hline$<20 \mathrm{~mm}$ & 3 & 27,3 \\
\hline $20-24 \mathrm{~mm}$ & 5 & 45,4 \\
\hline $25-29 \mathrm{~mm}$ & 1 & 9,1 \\
\hline$\geq 30 \mathrm{~mm}$ & 2 & 18,2 \\
\hline \multicolumn{3}{|l|}{ Degree of cervix opening } \\
\hline$<15 \mathrm{~mm}$ & 6 & 54,5 \\
\hline $15-19 \mathrm{~mm}$ & 1 & 9,1 \\
\hline$\geq 20 \mathrm{~mm}$ & 4 & 36,4 \\
\hline \multicolumn{3}{|l|}{ Evolution after cerclage } \\
\hline Bleeging & I & 9,1 \\
\hline Vaginal discharge & 5 & 45,4 \\
\hline PMR & 3 & 27,3 \\
\hline \multicolumn{3}{|l|}{ Term of birth (weeeks) } \\
\hline$<32$ & 1 & 9,1 \\
\hline $32-34$ & 3 & 27,3 \\
\hline $34-36$ weeks +6 days & 5 & 45,4 \\
\hline$\geq 37$ weeks & 2 & 18,2 \\
\hline \multicolumn{3}{|l|}{ Delivery mode } \\
\hline Vaginal & 2 & 18,2 \\
\hline Cesarean section & 9 & 81,8 \\
\hline
\end{tabular}

During the subsequent evolution of pregnancy, 3 pregnant (27.3\%) exhibited premature rupture of membranes respectively at 31 weeks +5 days, 33 weeks +4 days and at 34 weeks, which necessitated a second hospitalization. For these 3 patients, cortico therapy for fetal pulmonary maturation with $12 \mathrm{mg}$ of Betamethasone, antibiotic (Cefuroxim) have been administred. For membranes ruptures occurring between 33 and 34 weeks, fetal extraction was performed after 48 hours. Third patient with a gestational age of 31 weeks +5 days presented chorioamnionitis. Emergency cesarean section have 
been done. Mean gestational age at delivery was 36 weeks [31 weeks+ 5 days-38 weeks].

Average time between strapping and childbirth was 115 days or 15 weeks. Three children were born with a score of Apgar in the 1st minute less than 7 which improved in the 10th minute except the great premature born in 31 weeks +5 days. He was admitted to neonatology service where stayed for 15 days for a neonatal infection. Evolution was marked by healing.

\section{Discussion}

\section{Epidemiological characteristics}

There was mainly young pregnant, second pregnant and primiparous or nulliparous with a history of abortion, late miscarriage or premature delivery. According to the Royal College of Obstetricians and Gynecologists, the history of late miscarriage or pretherm births is a medium or high-risk factor for threat of miscarriage. ${ }^{6}$ Delabaere A. and Benifla $\mathrm{JL}^{8}$ in France reported 13 and 19\% of late miscarriage in their series, respectively. For our, $27.3 \%$ of history of late miscarriage are higher than those of these authors. This difference may be related to high proportion of abortion in our population, which weakens cervix. The average age of pregnancy during strapping was 20 weeks, while, respectivly for Benifla JL and Daskalakis G, a mean was 22 weeks, 1 day and 24 weeks, 4 days. ${ }^{8,9}$

\section{Strapping preparation}

Recommendations of french gynecolgist college in 2002 suggest waiting 48 hours after diagnosis of cervical incompetence before making cerclage to eliminate an infectious etiology and exclude premature childbirth. ${ }^{10}$ Delabaere A. showed that in absence of uterine contraction and inflammatory syndrom, waiting 48 hours did not improve the perinatal prognosis significantly compared to a strapping immediately.

\section{Therapeutic Aspects}

Cervical strapping can be done under loco-regional or general anesthesia according to two main techniques with or without colpotomy. The first technique described was Shirodkar, in which, after an anterior and posterior vertical colpotomy, test strip was passed through cervix under the vaginal mucosa and colpotomy were closed..$^{11}$ MacDonald proposed another technique to pass strip in the cervix circumferentially without reaching endocervix and without colpotomy. For all our patients, general anesthesia was practised and Mac Donald cerclage technique used.

We prefer it to Shirokar's technique because of its simplicity and speedly. Perrattan F. and his team ${ }^{5}$ prefer the Shirodkar type without however concluding superiority of one technique compared to other.

In our series, intervention lasted on average 12.27 minutes with a minimum of 8 minutes and a maximum of 20 minutes. Perrattan F. ${ }^{5}$ reported an average intervention time of $39+/-13$ minutes. Different operating techniques according to the teams could explain the variations of the operating times. Indeed, Perrattan uses the technique of Shirodkar longer to realize than that of Mc Donald that we have practiced.

\section{Following pregnancy}

Long-term operating suites were marked by a new hospitalization due to premature membrane rupture in $27.3 \%$ of our patients. This complication (MPR) occurred with the same proportions in the
Cockwell HA study. ${ }^{12}$ The rupture of the membranes is linked to a chorioamnionitis. MPR is often consequence of chorioamnionitis and not its cause. ${ }^{13}$ Occurrence of MPR and/or chorioamnionitis, cerclage more than 22 weeks with fetal membranes prolapsed had compromised pregnancy better evolution. ${ }^{14}$

According to Yip SK, ${ }^{15}$ there is a significant correlation between better continuation of the pregnancy and moment of cerclage. When this is done at 22 weeks or more than, pregnancy is extended by 13.5 days while it is extended by 122 days when it had been done more early.

For Alfirevic Z. ${ }^{14}$ in a Cochrane review more recent than YIP study, ${ }^{15}$ performing an emergency strapping whatever term in second trimester prolongs pregnancy on average from four to five weeks so, a reduction of the preterm birth before 34 weeks. Daskalakis G. ${ }^{9}$ Also noted an average pregnancy extension of 8.8 weeks. Althuisius $\mathrm{SM}^{16}$ and Cockwell HA ${ }^{12}$ reported a benefit of 7.7 weeks and 7 weeks of extension of pregnancy after, respectively. So emergency strapping significantly prolongs pregnancy and improves fetal outcome. In our series, we have an average extension of 115 days or 15 weeks. The risk of failure is highest for cervical dilatation more than $4 \mathrm{~cm}$ or if the greatest membranes hernia in vagina. ${ }^{17}$

\section{Neonatal prognosis}

It was generally good in our series because the age of births was most cases after 34 weeks, period of acquired pulmonary maturation. This would limit risks of prematurity by pulmonary immaturity. Bénifla JL recorded two neonatal losses ${ }^{8}$ in her study. However, since it was carried out in 1997, neonatal resuscitation was certainly less efficient than it was now.

In a meta-analysis including 12 trials involving 3328 patients and comparing strapping to long-term hospitalization, Alfirevic Z. did not find any statistically significant difference in perinatal mortality $(8.4 \%$ versus $10.7 \%$ ). He therefore concluded that cervical strapping reduces the incidence of preterm births in women at risk of preterm delivery without statistically significant reduction of perinatal or neonatal morbidity. ${ }^{14}$ Few studies have been done about possible long-term complications.

\section{Conclusion}

We can conclude that emergency cervical cerclage is an interesting option for patients who have a threat of late miscarriage (opened cervix, fetal membranes hernia) in the second trimester of pregnancy. This late emergency strapping prolongs pregnancy and decreases preterm births risk, which are difficult to take care of in limitedresource countries such as Côte d'Ivoire. We think that this therapeutic approach deserves to be encouraged.

\section{Acknowledgments}

None.

\section{Conflicts of interest}

The author declares that they do not have any conflicts of interest.

\section{References}

1. Delabaere A, Huchon C, Lavoue V, et al. Standardization of pregnancy loss terminology: Consensus of experts from the National College of Gynaecologists and obstetricians. J Gynécol Obstét Biol Reprod. 2014;43(10):756-763. 
2. World Health Organization. Neonatal and perinatal mortality: national regional and Global estimates. Geneva: WHO; 2006.

3. Blencowe $\mathrm{H}$, Cousens $\mathrm{S}$, Oestergaard $\mathrm{M}$, et al. National, regional and worldwide estimates of preterm birth. The Lancet. 2012;379(9832):21622172 .

4. Perrotin F, Lansac J, Body G. Strap placement in dealing with the threat of premature labor. J Gynecol Obstet Biol Reprod. 2002;31(7):5S66-5S73.

5. Perrotin F, Marret H, Ayeva-Derman M, et al. Second trimester therapeutic cervical cerclage: which technique is the most appropriate? A retrospectivestudy of 25 cases. J Gynecol Obstet Biol Reprod. 2002;31(7):640-648.

6. MRC/RCOG Working Party on Cervical Cerclage. Final report of the Medical Research Council/Royal College of Obstetricians and Gynaecologists multicenter randomised trial of cervical cerclage. $\mathrm{Br} J$ Obstet Gynaecol. 1993;100(6):516-523.

7. Delabaere A, Velemir L, Ughetto S, et al. Cerclage cervical en urgence au deuxième trimestre de la grossesse: expérience clermontoise. Gynecol Obstet Fertil. 2011;39:609-613.

8. Benifla JL, Goffinet F, Darai E, et al. Emergency cervicalcerclage after 20 weeks' gestation: a retrospective study of 6 years' practice in 34 cases. Fetal Diagn Ther. 1997;12(5):274-278.

9. Daskalakis G, Papantoniou N, Mesoqitis S, et al. Management of cervical insufficiency and bulging fetal membranes. Obstet Gynecol. 2006;107(2 Pt 1):221-226.
10. Perrotin F, Lansac J, Body G. Strap placement in dealing with the threat of premature labor. J Gynecol Obstet Biol Reprod. 2002;31(7):5S66-5S73.

11. Raynal P, Le Meaux JP, Epelboin S, et al. Early Prophylactic Strapping Technique for Hypoplastic Collars after Exposure to In utero DES. $J$ Gynecol Obstet Biol Reprod. 2005;34(6):572-580.

12. Cockwell H, Smith G. Cervical Incompetence and the role of emergency cerclage. J ObstetGynaecol Can. 2005;27:123-129.

13. Bessières B, Bernard P. Chorioamnionitis: Clinical, Biological and Forensic Implications. Gynecol Obstet Fertil. 2011;39:383-387.

14. Alfirevic Z, Stampalija T, Roberts D, et al. Cervical stitch (cerclage) for preventing preterm birth in singleton pregnancy. Cochrane Database Syst Rev. 2012;4:CD008991.

15. Yip SK, Fung H, Fung TY. Emergency cervical cerclage: A study between duration of cerclage in situ with gestation at cerclage, herniation of fore water, and cervical dilatation et presentation. Eur J Obstet Gynecol. 1998;78(1):63-67.

16. Althuisius $\mathrm{S}$, Dekker G, Hummel P, et al. Cervical incompetence prevention randomized cerclage trial: Emergency cerclage with bed rest versus bed rest alone. Am J Obstet Gynecol. 2003;189(4):907-910.

17. Abu Hashim H,Al-Inany H, Kilani Z. Areview of the contemporary evidence on rescue cervical cerclage. Int J Gynaecol Obstet. 2014;124(3):198-203.

Citation: Mohamed F,Abdoul K, Marie KJ, et al. Interest of late cerclage on open cervix with amniotic membrane's hernia in an African environment. Review of II collected cases at Yopougon University hospital in Abidjan (Ivory Coast, West Africa). Obstet Gynecol Int J . 20I8;9(6):5I4-5I8. 